\title{
Evaluation of the ecological efficiency of soil cultivation machines with innovative dynamic working bodies
}

\author{
Nozim I. Dzhabborov, Aleksandr V. Dobrinov*, and Galina A. Semenova \\ Federal Scientific Agroengineering Center VIM, branch in Saint Petersburg, Saint Petersburg, Russia
}

\begin{abstract}
The research results are related to the problem of enhancing the environmental safety of technical means in crop production. A research object is a tillage machine with standard and innovative dynamic working bodies. The research is aimed to a comparative ecological assessment of the efficiency of using typical and dynamic working bodies for surface tillage. The scientific novelty is represented by the regularities of changes in resistivity per unit of active frontal area of the investigated working bodies, inertia force and total kinetic energy, per hectare fuel consumption, fuel economy and reduction of emissions of toxic components at different speed modes of operation of the tillage unit. During the research, the methods of experimental research in the field, analysis and generalization of experimental data were used. It has been established that the resistivity per unit of active frontal area of a dynamic tillage working body with an energy-storage transmission mechanism within the range of speed variation from 2.22 to $3.33 \mathrm{~m} / \mathrm{s}$ decreases by $33-41 \%$ in comparison with a typical working body. With an increase in the speed of the tillage unit with standard working bodies from 2.22 to $3.33 \mathrm{~m} / \mathrm{s}$, the fuel consumption increases from 5.12 to $9.21 \mathrm{~kg} / \mathrm{ha}$. Within these limits of the speed of the tillage unit with dynamic tillage working bodies and energy-accumulating transmission mechanisms, the per hectare fuel consumption increases from 4.81 to $8.30 \mathrm{~kg}$. The use of dynamic working bodies on the tillage machine allows to save from 0.310 to $0.910 \mathrm{~kg}$ of fuel per 1 ha. Herewith, the decrease in the level of emissions of toxic components is $6-10 \%$, which ensures a decrease in the environmental load of soil-cultivating units during the cultivation of crop products.
\end{abstract}

\section{Introduction}

According to the latest statistics of the Federal Service for State Registration, Cadastre and Cartography (Rosreestr), the total arable land in Russia is more than 116.8 million hectares. Based on this circumstance, the size of emissions of toxic components from the use of energy facilities calculated during the agricultural year on a national scale can vary within $2.44-3.30$ million tons.

\footnotetext{
${ }^{*}$ Corresponding author: a.v.dobrinov@yandex.ru
} 
Research analysis shows that the amount of toxic components formed during the combustion of $1 \mathrm{~kg}$ of diesel fuel averages $57 \mathrm{~g}$, including carbon monoxide - 21 $\mathrm{g}$; hydrocarbons - 4g; nitrogen oxides $-18 \mathrm{~g}$; sulfur dioxide $-8 \mathrm{~g}$; aldehydes $-1 \mathrm{~g}$ and soot -5 [1-3].

An assessment of the fulfillment of agroecological requirements by tillage machines during their operation at high speeds is given in [4]. The article notes that soil cultivation is currently performed mainly at increased speeds from 10 to $15 \mathrm{~km} / \mathrm{h}$, while using combined multi-operational Russian and foreign machines, many of which are not adapted to local climatic conditions for a number of design parameters and technological modes. Excessive tillage causes a deterioration in the structure of the soil, while the formation of erosiondangerous particles is activated.

The article [5] describes methodological approaches to the development of systems for precision and adaptive landscape farming. The issues of a combination of technological operations, a decrease in the degree of swampy soils and rugged relief are considered.

Modern approaches to the use of energy - and environmentally efficient machine technologies and technical means are outlined in [6].

Evaluation of emissions of harmful substances in the field of technical service and repair of agricultural machinery is also important in its operation. For example, in [7], the results of assessing the concentration of harmful substances in the air in the working area of the galvanic section are given when hardening parts of harvesting machines with chromium plating.

The authors of [8] considered the possibilities of enhancing and enhancing the indicators for assessing the environmental safety of technical means during the procurement of green pressed fodder.

The studies of the authors of the article [9] were devoted to the assessment of the use of a self-regulating system for heating diesel fuel to reduce emissions of toxic components when burning diesel fuel by motor vehicles.

In the works of the authors of this work [10-14], ways of reducing the environmental load of agricultural machinery on the environment are also outlined, agroecological principles for the formation of a zonal system of soil cultivation are formulated, innovative soil-cultivating working bodies with dynamic properties are created, the use of which significantly reduces fuel consumption per unit of processed soil. area.

The analysis of research shows that the methods and means of ensuring the environmental safety of technical means in various sectors of the national economy, developed by scientists, turned out to be very effective for the development of the theory and practice of solving environmental problems.

At the present stage of development of agricultural production, further enhancement of environmental technologies and technical means is required to reduce emissions of harmful substances from mobile sources.

In this regard, the development of methods and ways to reduce the environmental load of agricultural machinery on the environment, in particular, based on the creation of machines for soil cultivation, seems relevant.

One of the effective ways to solve this problem is the development of innovative tillage working bodies and, accordingly, machines with dynamic properties that reduce fuel consumption per hectare and enhance the quality of soil cultivation.

At the IAEP, a branch of the Federal State Budgetary Scientific Institution FNATS VIM, we have developed and created experimental samples of innovative dynamic tillage working tools. Comparative experimental studies of typical and dynamic tillage working bodies and machines have been performed.

This article presents the results of a comparative environmental assessment of the efficiency of using dynamic and typical tillage working bodies and machines. 


\section{Materials and Methods}

The purpose of the experimental studies was to obtain experimental data for a comparative assessment of the ecological efficiency of using dynamic working bodies with an energystorage transmission device and standard typical working bodies for surface tillage, including loosening with the simultaneous cutting of weeds.

The experiments were performed on the territory of the research and production test site of the institute in the summer-autumn period of 2020.

Figure 1 shows the tillage working bodies for surface tillage.

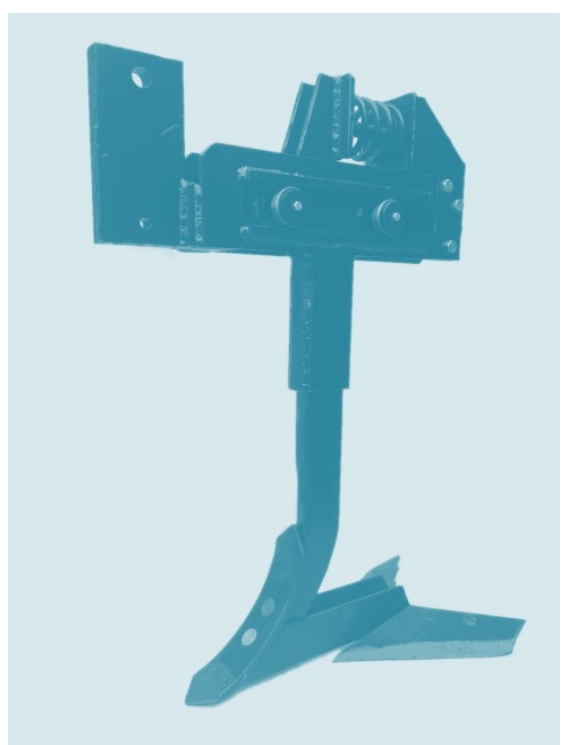

$\mathrm{a}$

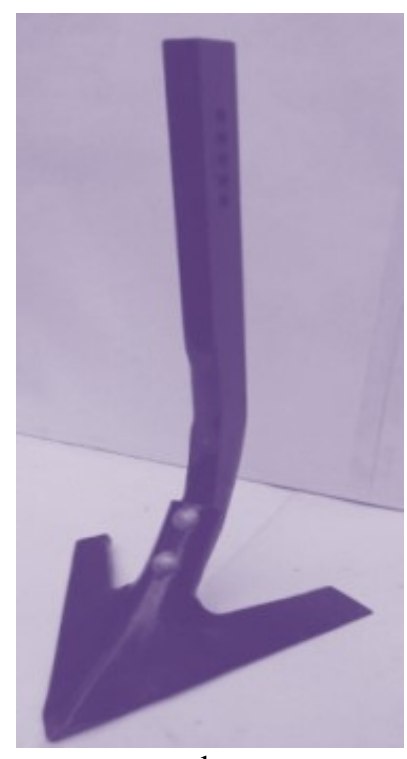

$\mathrm{b}$

Fig. 1. General view of a dynamic (a) with an energy-storage transmission device and a typical (b) tillage working bodies

The experiments were performed under certain soil conditions:

- soil type - soddy-medium podzolic;

- relief, degrees - 1-2;

- ridge of the surface of the field, $\mathrm{cm}-3-4$;

- soil hardness before processing in a layer of 5-20 cm - $0.85-1.0 \mathrm{MPa}$;

- soil moisture in the layer $0-10 \mathrm{~cm}-13.5 \%$, in the layer $10-20 \mathrm{~cm}-16.8 \%$.

The experimental data were processed pursuant to the method described in [15].

\section{Results and Discussion}

Based on the generalization of the experimental data, graphical dependences of the resistivity per unit of active frontal area of a typical and dynamic tillage working bodies on the speed of movement were constructed (Fig. 2). 


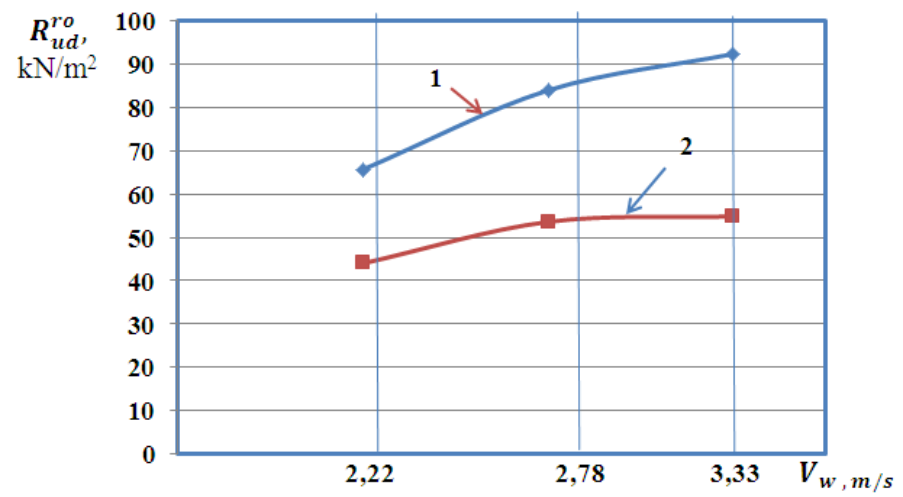

Fig. 2. Dependences of resistivity $R_{u d}^{r o}$ per unit of active frontal area of typical (1) and dynamic (2) tillage working bodies on the speed of movement $V_{w}$

The regularities of changes in the resistivity of tillage working bodies, described by the following empirical dependencies, have been revealed:

- typical working body:

$$
R_{u d}^{r o}=-15,64566 V_{w}^{2}+110,86047 V_{w}-103,24814
$$

- dynamic working body:

$$
R_{u d}^{r o}=-13,39148 V_{w}^{2}+84,10741 V_{w}-76,68787 .
$$

It was found that with an increase in the speed $V_{w}$ of movement from 2.22 to $3.33 \mathrm{~m} / \mathrm{s}$, the specific resistance $R_{u d}^{r o}$ of a typical tillage working body increases from 65.75 to 92.42 $\mathrm{kN} / \mathrm{m}^{2}$.

Within the same limits of speed change, the resistivity $R_{u d}^{r o}$ of a dynamic tillage working tool ranges from 44.03 to $54.89 \mathrm{kN} / \mathrm{m}^{2}$.

Analysis of the $R_{u d}^{r o}$ values shows that the specific resistance of a dynamic tillage working body, within the range of speed $V_{w}$ variation from 2.22 to $3.33 \mathrm{~m} / \mathrm{s}$, decreases by $33-41 \%$, in comparison with a typical working body.

Figure 3 shows the graphical dependence of the total inertia force on the vibration acceleration of dynamic tillage working bodies.

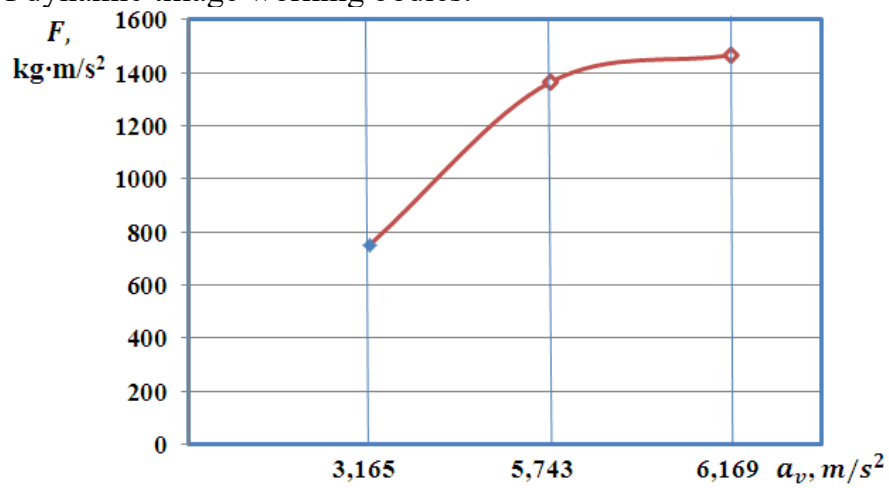

Fig. 3. Dependence of the total inertia force $F$ on the vibration acceleration $a_{v}$ of dynamic tillage working bodies

Using the Lagrange interpolation formula, based on the obtained experimental values, an empirical dependence was established that describes the regularity of the change in the total inertia force of dynamic tillage working bodies:

$$
F=-0,00544 a_{v}^{2}+237,64933 a_{v}-0,10161
$$


It has been experimentally established that with an increase in the speed of the soilcultivating unit from 2.22 to $3.33 \mathrm{~m} / \mathrm{s}$, the vibration acceleration $a_{v}$ of dynamic soilcultivating working bodies increases from 3.16 to $6.16 \mathrm{~m}^{2}$. Within the range of vibration acceleration $a_{v}$ variation from 3.16 to $6.16 \mathrm{~m}^{2}$, the total inertia force $F$ of the working bodies increases from 752.0 to $1465.75 \mathrm{~kg} \mathrm{~m} / \mathrm{s}^{2}$.

Figure 4 shows the dependence of the total kinetic energy of oscillation on the vibration speed of dynamic tillage working bodies.

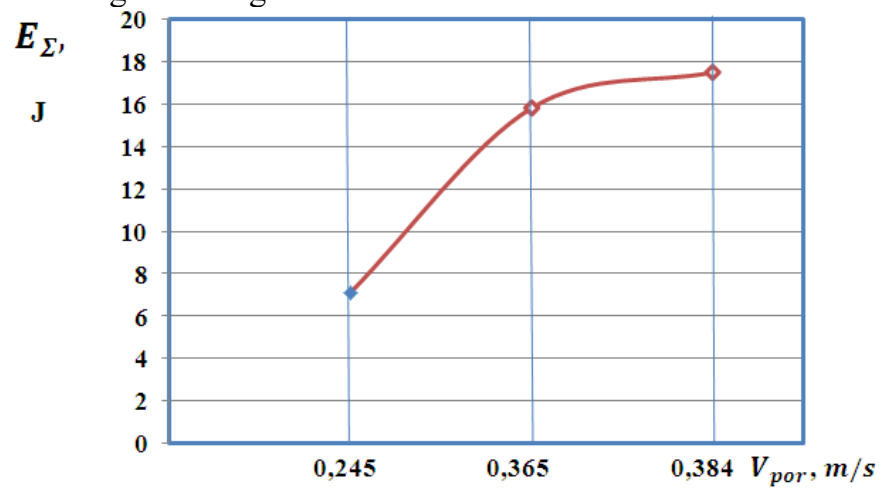

Fig. 4. Dependence of the total kinetic energy of oscillation $E_{\Sigma}$ on the vibration speed $V_{\text {por }}$ of dynamic tillage working bodies

The interpolation of the generalized experimental data made it possible to reveal the regularity of the change in the total kinetic energy of the vibration from the vibration velocity of the dynamic working bodies:

$$
E_{\Sigma}=115,61593 V_{\text {por }}^{2}+1,98262 V_{\text {por }}-0,29759 \text {. }
$$

It was found that when the vibration velocity $V_{\text {por }}$ changes from 0.24 to $0.38 \mathrm{~m} / \mathrm{s}$, the total kinetic energy $E_{\Sigma}$ increases from 7.12 to $17.51 \mathrm{~J}$. This indicates that at higher speeds, dynamic working bodies with an energy-storage transmission device generate more energy, which is used to create a dynamic impact on the cultivated layer of soil and enhance the quality of its processing.

Figure 5 shows the dependences of the specific fuel consumption per unit of the cultivated area of a tillage tool with dynamic and typical working bodies on the speed of its movement.

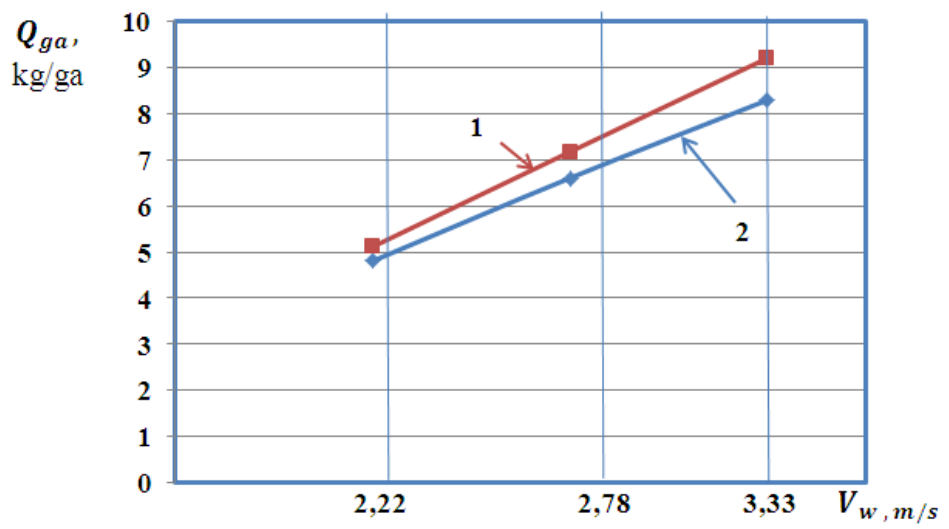

Fig. 5. Dependences of specific fuel consumption $Q_{g a}$ per unit of the cultivated area of a tillage tool with dynamic (2) and standard (1) working bodies on the speed $V_{w}$ of its movement. 
With an increase in the speed of the tillage unit with standard working bodies from 2.22 to $3.33 \mathrm{~m} / \mathrm{s}$, the fuel consumption $Q_{g a}$ increases from 5.12 to $9.21 \mathrm{~kg} / \mathrm{ha}$. Within these limits of the speed of the tillage unit with dynamic tillage working implements, the per hectare fuel consumption increases from 4.81 to $8.30 \mathrm{~kg}$.

Regularities of changes in specific fuel consumption per unit of treated area are revealed, which are described by empirical dependencies:

- a tillage unit with typical working bodies:

$$
\begin{aligned}
& Q_{g a}=0,01111 V_{w}^{2}+3,62300 V_{w}-2,97783 \\
& \text { - soil cultivating unit with dynamic working bodies: } \\
& Q_{g a}=-0,12753 V_{w}^{2}+3,85194 V_{w}-3,11278 .
\end{aligned}
$$

Figure 6 shows the graphical dependence of the amount of fuel consumption saving $\Delta Q_{g a}$ per 1 hectare of the cultivated area by a tillage machine with dynamic working bodies in comparison with typical working bodies on the speed of the machine.

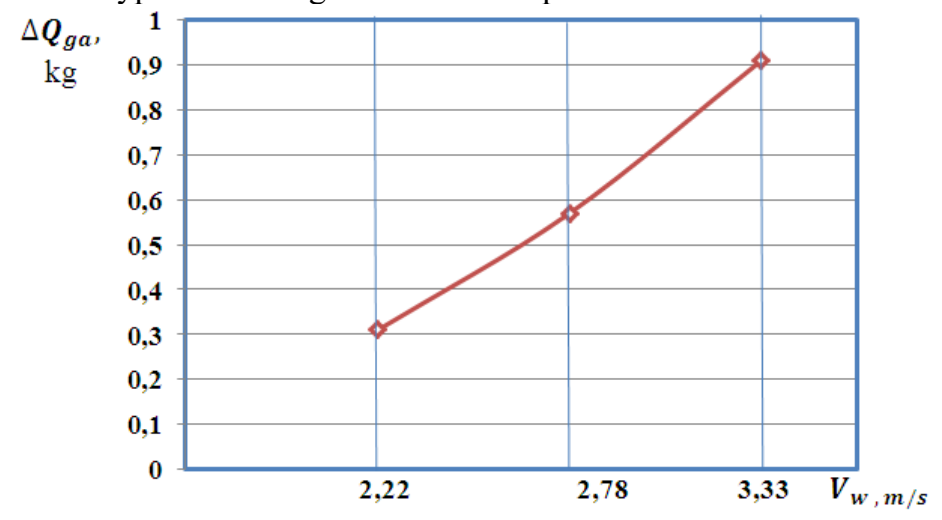

Fig. 6. Dependence of the amount of fuel consumption saving $\Delta Q_{g a}$ per 1 hectare of cultivated area by a tillage unit with dynamic working bodies in comparison with typical working bodies on the speed $V_{w}$ of the unit

As can be seen from Figure 6, within the range of movement speed of $V_{w}=2,22-$ $3,33 \mathrm{~m} / \mathrm{s}$, in comparison with typical working bodies, the use of dynamic working bodies in a tillage machine allows to save from 0.310 to $0.910 \mathrm{~kg}$ of fuel per ha.

The regularity of the change in the value of the fuel consumption saving $\Delta Q_{g a}$ on the speed $V_{w}$ of the tillage unit is revealed, which is described by the following empirical dependence:

$$
\Delta Q_{g a}=0,13865 V_{w}^{2}-0,22894 V_{w}+0,13495 .
$$

As noted above, when $1 \mathrm{~kg}$ of diesel fuel is burned, an average of $57 \mathrm{~g}$ of toxic components are emitted into the atmosphere.

The graphical (Figure 6) and empirical (formula 7) dependencies obtained in the process of processing and generalization of experimental data made it possible to establish the degree of reduction in the ecological load of the tillage machine with dynamic working bodies in comparison with the use of standard working bodies.

Figure 7 shows graphical dependences of the reduction in the amount of emissions of toxic components $\Delta M_{t k}$ (in grams, $\%$ ) during the operation of a machine-tractor tillage unit with dynamic working bodies on the speed $V_{w}$ of its movement. 


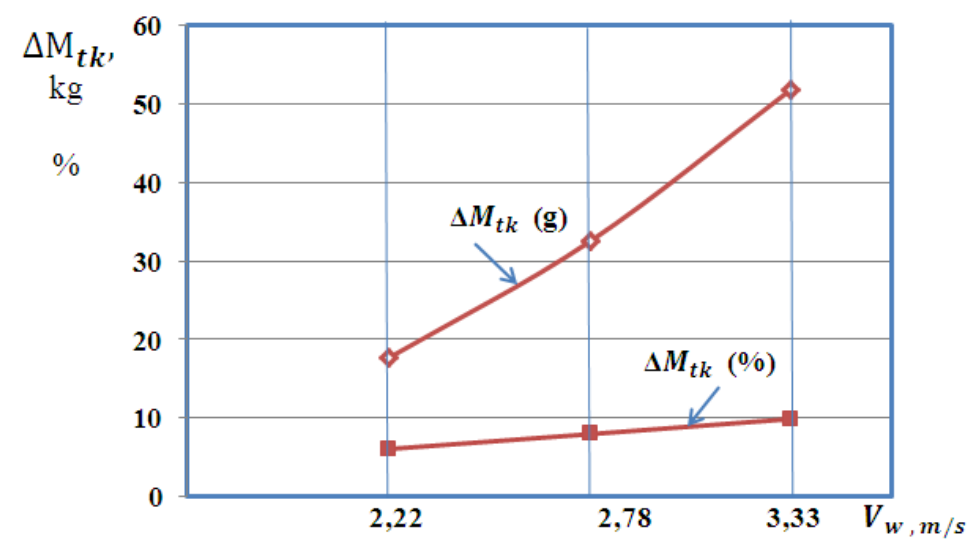

Fig. 7. Dependences of the amount of emissions of toxic components $\Delta M_{t k}$ of a machine-tractor tillage machine with dynamic working bodies on $V_{w}$ the speed of movement

Machine-tractor tillage machines with dynamic working bodies, in comparison with standard implements, correspond to the modern principles of ecological technologies, as they ensure the reduction of emissions of toxic components into the atmosphere. Experimental data indicate that when the speed of the soil cultivating unit with dynamic working bodies changes in comparison with typical working bodies from 2.22 to $3.33 \mathrm{~m} / \mathrm{s}$, the emissions of toxic components when processing 1 hectare of area decrease from 17.67 (by $6,05 \%)$ to $51.87 \mathrm{~g}(9.88 \%)$.

The revealed patterns of change in the magnitude of the decrease in the amount of emissions of toxic components into the atmosphere from the speed of movement of the tillage unit with dynamic working bodies are described by empirical dependencies:

$$
\begin{aligned}
& \Delta M_{t k}=7,87031 V_{w}^{2}-12,86938 V_{w}+7,45202,(\mathrm{~g}) \\
& \Delta M_{t k}=0,13718 V_{w}^{2}+2,68909 V_{w}-0,59586,(\%)
\end{aligned}
$$

As our research has shown, the use of dynamic working bodies with energy-storage transmitting devices on soil-cultivating implements for pre-sowing soil cultivation makes it possible to enhance its quality and achieve a reduction in fuel consumption when processing one hectare of arable land by $6-10 \%$, which ultimately ensures a decrease in environmental load of MTA crop production.

\section{Conclusion}

Tillage machines and working bodies used today in modern agricultural production do not fully meet the requirements of environmental safety. The enhancement of tillage machines, in particular their working bodies, should go along the path of enhancing their technological indicators and design parameters, on the basis of giving them the properties of dynamism and adaptability to various soil conditions.

The conducted research results confirm that the use of dynamic working bodies on soilcultivating implements, in comparison with standard working bodies, is of no small importance for reducing emissions of toxic components into the atmosphere. Thus, within the range of change in the speed of the soil-cultivating unit, from 2.22 to $3.33 \mathrm{~m} / \mathrm{s}$ with dynamic working bodies in comparison with typical working bodies, emissions of toxic components when processing 1 hectare of area decrease from 17.67 (by 6.05\%) to 51.87 grams $(9.88 \%)$. 


\section{References}

1. N. N. Krupenio, Calculation of pollutant emissions from vehicles running on gasoline and diesel fuel, as well as payments for these emissions, 38 (2006)

2. Online magazine about cars, https://7gear.ru/

3. The content of toxic emissions in the exhaust gases of engines, https://studexpo.ru/

4. V.N. Zvolinsky, Ecology and Agricultural Machinery, 2, 69-75 (2009)

5. D.A. Ivanov, N.G. Kovalyov, O.N. Antsiferova, Ecology and Agricultural Machinery, 2, 13-18 (2007)

6. A. Yu. Izmailov, Ya. P. Lobachevsky, O. A. Sizov, Agricultural machines and technologies, 4, 8 (2013)

7. A. E. Krupin, The international technical-economic journal, 2, 112-117 (2017)

8. S. Ivanov, S. Gakh, I. Skoniyechny, Ecology and agricultural technology, 2, 99-105 (2009)

9. A. M. Shuvalov, P. A. Telegin, T. N. Dementyeva, V. S. Ikonnikov, V. F. Kalinin, K. A. Nabatov, Ecology and agricultural equipment, 2, 244-248 (2009)

10. N. I. Dzhabborov, A. V. Dobrinov, A. M. Dementyev, Materials of the 7th international scientific and practical conference "Ecology and agricultural technologies: agroengineering solutions", 1, 43-47 (2011)

11. N. I. Jabborov, A. V. Dobrinov, D. S. Fedkin, Regional Ecology, 5, 23-27 (2015)

12. N. I. Dzhabborov, V. A. Eviev, A. V. Sergeev, G. A. Semenova, Technologies and technical means of mechanized production of crop and livestock products, 4(97), 56-65 (2018)

13. N. I. Dzhabborov, A. V. Sergeev, G. A. Semenova, Technologies and technical means of mechanized production of crop and livestock products, 1(98), 107-115 (2019)

14. N. I. Dzhabborov, A. V. Sergeev, A. M. Zakharov, A. N. Perekopsky, IOP Conference Series: Materials Science and Engineering. The collection of conference materials, Voronezh State University of Engineering Technologies, 012048 (2020)

15. A. M. Valge, N. I Jabborov, V. A. Eviev, Fundamentals of statistical processing of Experimental Data in the Conduct of researches on mechanization of agricultural production with examples on STATGRAPHICS and EXCEL, 140 (2015) 